\title{
The Most Preferred Food Labels Among Online Shoppers
}

\author{
Jean D. Gumirakiza ${ }^{1} \&$ Sarah M. VanZee ${ }^{1}$ \\ ${ }^{1}$ Department of Agriculture, Western Kentucky University, Bowling Green, KY, USA \\ Correspondence: Jean D. Gumirakiza, Department of Agriculture, Western Kentucky University, EST 237, 1906 \\ College Heights BLVD \# 410066, Bowling Green, KY 42101, USA. Tel: 1-270-363-7134. E-mail: \\ dominique.gumirakiza@wku.edu
}

Received: March 7, 2018

doi:10.5539/jas.v10n10p76

Accepted: July 24, $2018 \quad$ Online Published: September 15, 2018

URL: https://doi.org/10.5539/jas.v10n10p76

The research is financed by the USDA-NIFA.

\begin{abstract}
This study explains the most preferred food labels among online shoppers when purchasing food products. The study uses data from an online-based survey conducted in 2016. Participants are 1,205 online shoppers residing within the South region of the U.S. Using a binary logistic model, we found that the likelihood for online shoppers to consider food labels (other than prices) into their purchasing decision-making is 86 percent. Using a multinomial logit model, we found that the relative probability for "locally grown" labels to be the most important is 46 percent, 7 percent for "organically grown", 24 percent for both local and organic, and 23 percent for other kinds of labels. The most common other important labels among this last group include nutrition contents, and country of origin. This study is significant to fresh produce growers and agricultural marketers because it provides an explanation of food labels those online shoppers consider to be the most important when shopping for fresh produce. It is significant to food products regulators who are interested in enforcing regulations related to food labels. Future researchers will find this analysis useful when furthering knowledge about this increasingly popular market venue.
\end{abstract}

Keywords: food labels, local, online shoppers, organic

\section{Introduction}

Food labels play an important role in consumers' decision to purchase food products. In particular, local and organic food labels have become increasingly important to consumers. In part, this stems from the locavore movement, the desire to eat healthier, and wanting to know the origins of the food. In recent years, interestingly, online shopping has attracted some health-conscious consumers. A study by Hsu and Chen (2011) concluded that one of the primary motivations for shopping online for food products was to seek for healthier products. If consumers are most concerned with eating healthy, then which food label is the most important? Several previous studies like Chen (2015); Lang et al. (2014); and Lee et al. (2013) ascertained that food labels such as local and organic have significant impacts on consumers' purchasing decisions. Unlike previous studies, this study focuses primarily on the preferences of online shoppers. In this study, online shoppers are defined as those consumers who made at least two online purchases within six months prior to participating in this study. In other words, we consider you as an online shopper if you placed at least two online orders within the last six months.

This study describes the characteristics of online shoppers, explains the likelihood of considering food labels when purchasing food products, and determine relative probabilities for a specific food label to be the most important to online shoppers. The study identifies and explains consumer characteristics that have significant effects on preferences for foods labeled local, organic, or both, relative to any other food label. Findings from this study are important for food growers, processors, and agricultural marketers/sellers. It focuses on explain food labels with increasingly popular trends in the local agriculture community, the locavore, and organic movement. This study is also directed towards online shopping, which is becoming an increasingly potential marketplace for fresh produce (Neilson Holdings PLC, 2015). Knowing whether food labels are a significant factor for the online shoppers when making purchasing decisions is important. Likewise, the knowledge about the most preferred food labels and consumer characteristics with significant effects is vital. Future researchers will find this study to be helpful in furthering studies related to this topic. 


\section{Literature Review}

Online shopping has become increasingly popular for several reasons. Hsu et al. (2011) found that the main reasons for shopping online are convenience, safety, health related reasons, and the variety of food products in the online market. Other studies like those of Lian and Yen (2014), and Karim (2013) also posited that several consumers shop online because it is convenient for their lifestyle. The health and environmental benefits surrounding "local" and "organic" labels make online shopping for food a unique opportunity for both producers and consumers.

Are consumers willing to pay more for a product because it is labeled local, organic, or both? According to Zhang et al. (2016); VanLoo et al. (2011); Sackett et al. (2016); De-Magistris et al. (2016); and Curtis et al. (2014) consumers are willing to pay more for their preferred label. In a study performed at the University of Connecticut, it was found that college students were willing to pay 1-2\% more for local and organic food (Bruno \& Campbell, 2016). A study performed in Tennessee by Baryeh, (2015) found that over 75 percent of consumers were willing to pay at least a little more for produce that was labeled "organic". Another study by Larceneux et al. (2012) stated that when the labels "local" and "organic" are both offered most people value locally grown food over organic foods. Other studies have found that consumers particularly in the United States prefer local food products and are willing to pay significantly more for food labeled "local" (Byrd et al., 2017). Contrarily; a different study performed in the northeast United States found that consumers were willing to pay more for food labeled "organic" rather than "local" (Chen, 2015). Heng et al. (2016) reported that too many labels can actually discourage consumers from purchasing products. There are many factors that contribute to the willingness to pay more for organic and local foods such as environmental concern, income, and knowledge of a product.

Who exactly is purchasing foods that are labeled "local" and "organic"? Baryeh (2015); Cholette et al. (2013); and Oraman (2014) found that women were more likely to purchase foods labeled "organic". Nasir et al. (2014) found that in addition to females, younger, educated, and relatively affluent consumers are also more likely to purchase organic foods. Racine et al. (2012); and Stanton et al. (2012) found that rural residents, older, and affluent individuals are more likely to buy local foods. Another study added that those who have supportive attitudes toward local food were more likely to purchase food labeled "local" (Feldmann \& Hamm, 2015). The apparent difference between many of the studies was that younger individuals preferred foods labeled "organic" while older individuals preferred foods labeled "local."

Along with the labels "local" and "organic" there are other labels that influence consumers to buy a product. Studies performed by Pouta et al. (2010); and VanLoo et al. (2014) found that consumers prefer labels related to animal welfare rather than organic labeling. Their studies also stated that consumers will even pay more for those items with animal welfare related labels. These animal welfare labels referred to the way the animal was raised, such as grass fed, free range, and other labels related to enhancing the welfare of their meat products (DeJonge \& Trijp, 2013b). Other studies have shown that there is opportunity for agricultural marketers to consider these labels when marketing many meat products (DeJonge \& Trijp, 2013a; Vanhonacker \& Verbeke, 2014).

Labels concerning Genetically Modified Organism (GMO) are becoming increasingly important to consumers and started impacting their purchasing decisions. Center for Food Safety (2017) indicates that 64 countries require the labeling of genetically modified products. In those countries, there are different regulations referring to what percentage of the product can contain genetically modified products. For example, in the European Union if a product contains more than 0.9 percent of a genetically modified organism, it must be labeled (Dobnik et al., 2015). There are some studies in the United States have found that the majority of consumers are in favor of GMO labeling (Berning \& Campbell, 2016; Hemphill \& Banerjee, 2015; Wunderlich \& Gatto, 2015). Hallman et al. (2013) indicated that even though the majority of Americans have very little knowledge about genetically modified foods, they desire a required GMO label on genetically modified foods. In the United States, genetically modified foods must be heavily tested before being introduced into the market (Acosta, 2014).

Another food label that is important to consumers when purchasing foods is the nutritional content label. Several studies like those of Hwang et al. (2016); and Newman et al. (2017) found that in order to eat healthier more consumers are making purchasing decisions based on nutrition labels. Many countries have even passed laws enforcing package nutrition labels. Such labels are supposed to help consumers make informed purchases. Findling et al. (2017); and Ducrot et al. (2016) noticed that many companies in the U.S. are using package nutrition labeling as a marketing technique by giving consumers the information they are looking for on the front of the package. 


\section{Methodology}

\subsection{Data Collection Process}

The data used in this analysis were collected using an online-based survey. Participants are 1,205 online shoppers; defined as those consumers who made at least two purchases in the online market six months before receiving the survey. We limited this study to those online shoppers who were located in the Southern region of the United States The states that are in this region are: Arkansas, Delaware, Florida, Georgia, Kentucky, Louisiana, Maryland, Mississippi, North Carolina, Oklahoma, South Carolina, Tennessee, Texas, Virginia, West Virginia, and the District of Columbia (U.S. Census Bureau, 2016). For a better representation, each state in this region is proportionally represented in the sample based on its population.

We created survey questions in the Qualtrics software. This software includes features that allows accurate profiling and tracking each respondent. The features are important in ensuring that respondents are actually meet desired characteristics for this study. Furthermore, using this software allowed us to design questions with advanced branching logic and randomizing question options. Because of these integrated features, we were able to avoid possible bias among study participants. In February 2016, we conducted a pilot study to test the capacity of the survey to collect good data. In this pilot study, 100 online shoppers participated in this pilot exercise. The pilot study allowed us to rephrase some questions and prompted a need to include the attention-check questions. We also added a number of questions aimed at eliminating inattentive participants. We set the software in way that any survey taker with incorrect answer to such questions was excluded automatically.

We consulted the Qualtrics company to collect data. This company is a professional survey software provider with extensive experience data collection. The company works in partnership with many market-related entities who provide respondents with specific sample requirements. Qualtrics distributed the survey between March and June 2016 to individuals who meet our criteria: Be at least 18 years old, having made at least two online purchases within six months before taking the survey, and being located within the U.S. South region. We checked every internet protocol location and used an advanced digital fingerprint technology in order to assure both quality and validity of the data. The survey remained open until we reached 1,205 surveys that were fully completed, verified, and validated.

\subsection{Model Specification}

This analysis uses two logit models: Binary and Multinomial. First, we used the binary logit model to explain the likelihood for an online shopper to consider food labels other than prices as important in their purchasing decision-making process. The dependent variable consists of two values; 0 and 1 where one is for "yes, I consider food labels other than prices as important in their purchasing decision-making process" and zero otherwise. We followed a modeling strategy that Wooldridge (2009) proposed in the form illustrated in (1) below:

$$
P(y=1 \mid X)=G\left(\beta_{0}+\beta_{1} X_{1}+\beta_{2} X_{2}+\beta_{3} X_{3}+\ldots+\beta_{k} X_{k}\right)=G\left(\beta_{0}+X \beta\right)
$$

where $y$ is the response that we observe as reseacher and $G$ is a logistic function taking on values strictly between zero and one for all real numbers $z$. The $G$ takes the following functional form:

$$
G(z)=\exp (z) /[1+\exp (z)]
$$

The logistic model is derived from an underlying latent variable model. We let $y^{*}$ be an unobseved, or latent, variable determined by

$$
y^{*}=\beta_{0}+X \beta+e, y=1\left[y^{*}>0\right]
$$

where, $y=1\left[y^{*}>0\right]$ defines the binary outcome and serves as an indicator function which takes on a value of one if the event in brackets is true and zero otherwise. We assume the error term $e$ to be independent of $X$ and to have a standard logistic distribution.

Second, we used Multinomial logistic model to determine relative probabilities for specific food labels to be considered as the most preferred. The theoretical modeling strategy in this section follows Kennedy (2009); and Train (2009). This model makes it possible to estimate relative likelihood for an online shopper to prefer a particular food label among four unordered options. We assume that the respondents behave rationally when making decisions. It means that they have complete and transitive preferences and choose the best option they believe maximize their utility (Mas-Colell et al., 1995). We also assume that adding a new label option to the set has no impact on relative odds among choices already in the set. This what Train (2009) referred to the Independence from Irrelevant Alternatives (IIA) holding true. We finally assume that the chooser's utility from 
the existing choice set is a linear function of his/her characteristics, plus an error term. Hence, Equation (4) shows the utility $\left(U_{i j}\right)$ function form,

$$
U_{i j}=V_{i j}+\varepsilon_{i j}, \text { for } i=1, \ldots I \text { and } j=1, \ldots J
$$

The $V_{i j}$ in (1) is a deterministic component of the utility, $\varepsilon_{i j}$ is a random component, $i$ stands for respondent, and $\mathrm{j}$ stands for the label options. Respondents had four options to choose from. They were asked "when purchasing food products, which label is the most important?" 1 = Locally grown regardless of production methods, $2=$ Organically grown regardless of origin, $3=$ Both locally and organically grown, $4=$ Other (please specify).

The $\varepsilon_{i j}$ term is assumed to be independently and identically distributed in accordance with an extreme value $F\left(\varepsilon_{i j}\right)$ $=\exp \left[-\exp \left(-\varepsilon_{i j}\right)\right]$. This allows for the logit model to be appropriate (Kennedy, 2008).

There is a latent variable or indirect utility which drives the chooser's decision. The indirect utility for respondent $i$ to choose a specific label option $j$ is:

$$
V_{i j}^{*}=\beta^{\prime} X_{i j}+\mu_{i j} \text {, for } i=1, \ldots I \text { and } j=1, \ldots J
$$

$X_{i j}$ in (5) is a vector of respondent's characteristics, $\beta$ is a vector of the parameters we estimate and differs across four options. The $\mu_{i j}$ accounts for unobserved factors. Because individual's utility is unobservable, individual's choice $y_{i}$ (observable) indicates an option that maximizes his/her utility. That is:

$$
\left[y_{i}=1 \Leftrightarrow \mathrm{V}_{i 1}^{*}>V_{i j}^{*} \forall j, y_{i}=2 \Leftrightarrow \mathrm{V}_{i 2}^{*}>V_{i j}^{*} \forall j, \ldots, y_{i}=J \Leftrightarrow \mathrm{V}_{i J}^{*}>V_{i j}^{*} \forall j\right]
$$

The probability $(P)$ that a shopper $i$ chooses an option $j$ is shown as:

$$
P_{i j}=P\left(y_{i}=j\right)=\frac{\exp \left(\beta_{k}^{\prime} X_{i j}\right)}{\sum_{j} \beta_{k}^{\prime} X_{i j}}
$$

We obtain the $\beta$ 's by setting $\beta_{j^{*}}=0$ for reference option; $j^{*}$. In this study, the "Other" option is the reference category. From (7) above, the $\beta$ 's (in comparison with the reference outcome $j^{*}$ ) are computed as follows:

$$
\frac{\delta \log \left(P_{j} \mid P_{j^{*}}\right)}{\delta X_{k}}=\beta_{i k}-\beta_{j^{*}}
$$

which reduces to:

$$
\frac{\delta \log \left(P_{j} \mid P_{j^{*}}\right)}{\delta X_{k}}=\beta_{i k}
$$

The marginal effect of an independent variable $X_{k}$ on the choice probability for an alternative $j$ is given by,

$$
\frac{\delta P(y=j \mid X)}{\delta x_{k}}=P\left(\beta_{j k}-\bar{\beta}_{j k}\right)=P\left(\beta_{j k}-\frac{\sum_{j} \beta_{j k}}{J}\right)
$$

A positive parameter $\beta_{j k}$ for a continuous variable indicates that the relative likelihood to choose the corresponding $j$ increases compared to that of choosing $j^{*}$. For dummy variables, the $\beta$ 's are the probability differences between $X_{i j}$ values of zero and one (Schmidheiny, 2007).

We hypothesize that each independent factor has no significant effect (the null hypothesis) on the likelihood of preferring a specific $j$ as the most important food label relative to the $j^{*}$. That is $H_{0} \equiv \beta_{k j}=0 ; \forall k=1, \ldots K ; j=$ $1, \ldots J$ for $K$ explanatories and $J$ label options. We then hypothesize that each independent variable has significant effect (the alternative hypothesis) on the likelihood of preferring a specific $j$ as the most important food label relative to the $j^{*}$. That is; $H_{1} \equiv \beta_{k j} \neq 0 ; \forall k=1, \ldots K ; j=1, \ldots J$ for $K$ explanatories and $J$ label options.

\section{Results}

\subsection{Descriptive Statistics}

in this study, we asked several questions about consumer characteristics. Table 1 shows descriptive statistics for those characteristics with significant effects on the likelihood of considering food labels and/or on the most important labels when making purchasing decisions. To make sure that we don't include independent variables that are highly correlated with each other, we tested for the correlation and found that the highest correlation coefficient is 0.59 between the "InterestLevelFreshness" (levels of interests in the freshness of the produce) and "InterestLevelLocalFP" (levels of interests in locally grown fresh produce). According to Wooldridge (2009), this indicates a weak correlation as it is less than 0.80 . Statistics related to each of the four label options are in Table 1 (see 2-5 columns). For example, an average respondent whose most preferred food label is "local" is 49 years old, is willing to pay $\$ 6.64$ for locally grown and $\$ 4.69$ for the imported one. Females are 63 percent of the "local" funs, married are 58 percent, and Caucasians are 90 percent. We found that 26 percent of these shoppers 
are not interested in buying fresh produce online while 22 are very interested. As in Gustat et al. (2015), we use "fresh produce" to refer to fruits and vegetables.

Table 1. Consumer characteristics by the most preferred food labels

\begin{tabular}{llllll}
\hline Markets & Locally Grown & Organically Grown & Both Local and Organic & Other Labels & Total \\
\hline Age & 49 & 41 & 46 & 46 & 47 \\
Female & 0.63 & 0.58 & 0.66 & 0.56 & 0.62 \\
Married & 0.58 & 0.49 & 0.57 & 0.55 & 0.56 \\
Locavore & 0.81 & 0.60 & 0.77 & 0.59 & 0.72 \\
Education & 3.36 & 3.50 & 3.38 & 3.35 & 3.36 \\
Caucasian & 0.90 & 0.73 & 0.78 & 0.78 & 0.82 \\
WTPLocalFP & 6.64 & 8.00 & 7.34 & 6.22 & 6.90 \\
WTPForeignFP & 4.69 & 6.32 & 5.68 & 5.40 & 5.32 \\
InterestedInCSA & 0.52 & 0.67 & 0.65 & 0.42 & 0.55 \\
AboveMeanIncome & 0.34 & 0.48 & 0.36 & 0.37 & 0.37 \\
InterstLearnFPMarket & 0.85 & 0.83 & 0.89 & 0.62 & 0.81 \\
InterestOnlineShopFP & 1.88 & 2.28 & 2.21 & 1.90 & 2.02 \\
InterstLearnFPMarket & 0.85 & 0.83 & 0.89 & 0.62 & 0.81 \\
InterestLevelLocalFP & 3.98 & 3.88 & 4.20 & 3.32 & 3.87 \\
InterestLevelOrganic & 2.80 & 4.15 & 4.09 & 2.63 & 3.27 \\
InterestLevelFreshness & 4.52 & 4.32 & 4.54 & 3.98 & 4.38 \\
MonthlySpendFreshProduce & 49.6 & 78.4 & 68.4 & 48.1 & 57.8 \\
Total & 462 & 151 & 318 & 274 & 1205 \\
\hline
\end{tabular}

As presented in Table 1 above, an average online shopper who participated in this study is 47 years old. Participants consisted of 62 percent females, 56 percent married, and 82 percent Caucasians. We report that 55 percent of the respondents are interested in joining the Community Supported Agriculture (CSA) programs. This includes those who are already subscribers. This finding suggests that those farmers who participate in the CSA programs have a potential market in the online environment. We also report that 81 percent of online shoppers are interested in learning about direct-to-consumer market outlets for fresh produce (fruits and vegetables) in their communities. This suggests that fresh produce growers and/or agricultural marketers/sellers may increase their market shares by using educational and marketing strategies targeting online shoppers.

As for being interested in shopping fresh produce online, we found that 22 percent are not interested at all, 48 percent might be interested. What is encouraging to the online sellers of fresh produce is that 30 percent of respondents indicated that they are definitely interested in shopping for fresh produce online. The WTPLocalFP variable averages the amounts of money that the online shoppers are willing to pay for a pound of locally grown green beans, sweet corn, tomatoes, strawberries, and kale. The WTPForeignFP variable is for the same imported products, but imported from abroad. We found that, on average, online shoppers are willing to pay $\$ 6.90$ for locally grown and $\$ 5.32$ for the imported ones. We found that the level of interests in the freshness of food product is very high (very interested) across all four segments. The overall level of interest in freshness is 4.38 on a scale of 1-5; five being extremely interested. We realized that those shoppers whose primarily food label is "organic" have the highest monthly expenditure on fresh produce; $\$ 78.4$ on average.

\subsection{Regression Results}

\subsubsection{The Likelihood for Consideration of Food Labels, Other Than Prices/Costs}

We used a binary logit model to explain whether or not food labels are a factor in the shopping decisions online shoppers make. Used responses to the question: When shopping for food products, do you give consideration to labels, other than prices/costs? Yes (1) or No (0). Table 2 shows results from this model. We obtained the results in Table 2 by using the Stata Software. 
Table 2. Coefficient estimates and marginal effects from a binary logit model

\begin{tabular}{lll}
\hline Variables & Beta Coefficients & Marginal Effects: $\operatorname{Pr}(\mathrm{y}=1)=.8586$ \\
\hline Age & $.0105271^{*}$ & $.0013425^{*}$ \\
Female & $.4921902^{* * *}$ & $.06545^{* * *}$ \\
Married & -.2602787 & -.0328404 \\
Locavore & .2819703 & .0375574 \\
Education & .1101968 & .0140537 \\
Caucasian & $.732921^{* * *}$ & $.1098247^{* * *}$ \\
InterestCSA & .0289089 & .0036903 \\
WTPLocalFP & $.1678388^{* * *}$ & $.0203714^{* * *}$ \\
WTPForeignFP & $-.1439136^{* * *}$ & $-.0174675^{* * *}$ \\
AboveMeanIncome & -.1681102 & -.0218019 \\
InterestLevelOrganic & $.2985653 * * *$ & $.0380769^{* * *}$ \\
InterestLevelLocalFP & .1188556 & .015158 \\
InterestOnlineShopFP & $-.2453404 * *$ & $-.0312889^{* *}$ \\
InterestLearnFPMarket & $.6000487 * * *$ & $.0866263^{* * *}$ \\
InterestLevelFreshness & $.238599^{* *}$ & $.0304292^{* *}$ \\
MonthlySpendFreshProduce & -.0004877 & -.0000622 \\
Constant & $-2.498097^{* * *}$ & \\
\hline
\end{tabular}

Note. The $*,{ }^{* *},{ }^{* *}$ denote significance at the $10 \%, 5 \%$, and $1 \%$ level, respectively.

The binary logit regression model above shows the results of those who answered yes to giving consideration to labels other than price and cost, when purchasing food products. We estimated that the probability of food labels - other than prices - being a significant factor into the purchase decision-making is 86 percent. This result indicates that a vast majority of consumers in the online marketplace appreciates the information presented to them as labels. The information about food production methods and places of origin is very important. The results indicate that those who significantly give consideration to food labels are older, Caucasians, and primarily females. More specifically, additional ten years of age increases the likelihood to label consideration by almost 0ne percent. The likelihood is almost seven percent higher for females and 11 percent higher for Caucasians.

Likewise, we found that higher interests in learning about direct-to-consumer market outlets, in organic products, and in product freshness increase the likelihood of considering food labels very important. On the other hand, we found that individuals with interests in shopping for fresh produce online do not care much about food labels; other than the prices. This result seems to suggest that this particular segment of customers might have other concerns about online market for fresh produce which are more important that food labels. We found that income, marital status, being locavore, and education have no significant effect on the probability of considering food labels to be important.

\subsubsection{Probabilities for Specific Food Labels to Be the Most Preferred}

One of the questions we asked respondents was: When purchasing food products, other than prices, which label is the most important to you? There were four discrete options to choose from: $1=$ Locally grown, $2=$ Organically grown regardless of origin, 3 = Both locally and organically grown, $4=$ Other (please specify). We used a multinomial logistic model in which the fourth option is the "base category." Results in Table 3 below are coefficient estimates we generated using Stata Software. 
Table 3. Coefficients from the MLOGIT regression

\begin{tabular}{llll}
\hline Variables & Local & Organic & Local\&Organic \\
\hline Age & 0.00313 & 0.000558 & 0.00924 \\
Female & 0.227 & 0.0615 & 0.237 \\
Married & -0.0799 & $-0.843^{* * *}$ & -0.347 \\
Locavore & $0.772^{* * *}$ & $-0.792^{* * *}$ & 0.105 \\
Education & 0.0681 & 0.0551 & 0.0673 \\
Caucasian & $0.907^{* * *}$ & 0.169 & 0.350 \\
InterestCSA & 0.0391 & 0.223 & 0.00939 \\
WTPLocalFP & $.1404728^{* * *}$ & $.1628733^{* * *}$ & $.0769073^{*}$ \\
WTPForeignFP & $-.1258429^{* * *}$ & $-.1145781^{* *}$ & $-.0774856^{* *}$ \\
AboveMeanIncome & -0.317 & $0.248^{*}$ & -0.244 \\
InterestLevelOrganic & $-0.141^{* * *}$ & $1.427 * * *$ & $1.024 * * *$ \\
InterestLevelLocalFP & $0.385^{* * *}$ & $-0.345^{*}$ & 0.0489 \\
InterestOnlineShopFP & $-0.237^{* *}$ & -0.00759 & -0.0288 \\
InterstLearnFPMarket & $0.815^{* * *}$ & 0.340 & $0.663^{* *}$ \\
InterestLevelFreshness & $0.272^{* * *}$ & $-0.300^{* *}$ & $-0.0778^{*}$ \\
MonthlySpendFreshProduce & -0.000781 & 0.00163 & -0.00130 \\
Constant & $-3.387^{* * *}$ & $-3.133^{* * *}$ & $-4.415^{* * *}$ \\
\hline
\end{tabular}

Note. The $*,{ }^{* *},{ }^{* *}$ denote significance at the $10 \%, 5 \%$, and $1 \%$ level, respectively.

The Multinomial Logit regression model above compares the characteristics of consumers who prefer local, organic, or both local and organic to those whose important food labels were not listed. Those individuals who prefer "local labored food product" are locavore, Caucasians, are interested in learning about various direct-to-consumer market outlets, and expect the products to be fresh. This finding may be due to the shift towards eating locally grown foods because of their foreseen benefits. We further found that affluent consumers consider "organic label" to be a significant factor when making food purchase decision. This result suggests that such customers would be willing a premium for organically grown food products. Finally, married individuals are less likely to principally prefer organic labels. By running a $\mathrm{mfx} 2$ command after the Stata command above, we found relative probabilities for each of the four options and the marginal effects as presented in Table 4 below. These marginal effects indicate the percentage changes per an incremental increase in the corresponding continuous or categorical and probability difference for dummy ( 0 or 1$)$ variables.

As presented in Table 4, we found that the relative likelihood for an online shopper to primarily consider labels with "locally grown" food products is 46 percent. Those shoppers who consider themselves to be locavore are 20 percent more probable to prefer labels showing that food products are locally grown. This finding corresponds to our expectations. One would expect that an individual whose diet consists only or principally of locally grown or produced food to almost always be looking for products with "local" labels. They seem to care less about how the food products were produced. In fact, we found that locavore consumers are less likely to consider labels with organically grown food products as the most important.

Another significant finding from this study is that compared with other races, Caucasians are almost 18 percent more likely to prefer food products labeled "locally grown." This result is different from Zepeda and Li (2006) who concluded that ... race, ... had no significant impact on the probability of buying local food. The similar findings are that gender, income, age, and education are insignificant factors. In addition, we found that those respondents with high interests in shopping online for fresh produce disfavor "locally grown" food labels. This finding might suggest that online shoppers are not necessarily limited to products being locally grown as long as they are still fresh at the delivery date. 
Table 4. The marginal effects from the multinomial logit model

\begin{tabular}{lllll}
\hline Variable & Locally Grown $=46 \%$ & Organically Grown $=07 \%$ & Local\&Organic $=24 \%$ & Others $=23 \%$ \\
\hline Age & -.00026 & -.000207 & .0013475 & -.0008741 \\
Female & .0285153 & -.0067938 & .0176097 & -.0393312 \\
Married & .0450474 & $-.0458535^{* * *}$ & -.0408554 & .0416615 \\
Locavore & $.2003457^{* * *}$ & $-.0905623^{* * *}$ & -.0422752 & $-.0675082^{* *}$ \\
Education & .0077623 & .00027 & .0039668 & -.0119991 \\
Caucasian & $.1749157^{* * *}$ & -.020943 & -.0280285 & $-.1259442 * * *$ \\
InterestCSA & .0020544 & .0122352 & -.0061486 & -.008141 \\
WTPLocalFP & $.021291^{* * *}$ & $.0045053^{* * *}$ & -.00423 & $-.0215662 * * *$ \\
WTPForeignFP & $-.0190442^{* * *}$ & $-.00198^{* *}$ & .0016894 & $.0193348 * * *$ \\
AboveMeanIncome & -.05956 & $.0301724 *$ & -.0147021 & .0440977 \\
InterestLevelOrganic & $-.1913006^{* * *}$ & $.0751784 * * *$ & $.1817105 * * *$ & $-.0655883 * * *$ \\
InterestLevelLocalFP & $.1002574 * * *$ & $-.0333584 *$ & -.0282115 & $-.0386874 * *$ \\
InterestOnlineShopFP & $-.0553733^{* *}$ & .0070686 & .0211435 & .0271612 \\
InterstLearnFPMarket & $.1223547^{* * *}$ & -.0123278 & $.0332297 * *$ & $-.1432566 * *$ \\
InterestLevelFreshness & $.0849943^{* * *}$ & $-.0252186^{* *}$ & $-.0397528^{*}$ & -.0200228 \\
MonthlySpendFreshProduce & -.0000982 & .0001441 & -.000179 & .0001331 \\
\hline Note. The $* * *, * * *$ & &
\end{tabular}

Note. The $*,{ }^{* *},{ }^{* *}$ denote significance at the $10 \%, 5 \%$, and $1 \%$ level, respectively.

As expected, we found that those with greater interests in local produce indicated that labels with "locally grown" play a significant role in their purchasing decision. This finding is similar to Feldmann and Hamm (2015) who reported that consumers with supportive attitudes toward local food were more likely to purchase food labeled "local". On a 1-5 scale, one additional level of interest in local fresh produce increases the likelihood of considering such labels by 10 percent barely. Similarly, those shoppers with high interests in learning about direct-to-consumer markets outlets in their community are more probable to prefer "locally grown" labeled food products. An extra level in these interests increases the likelihood by almost 12 percent. Obviously, we found that shoppers with high interests in the freshness of the food products consider "locally grown" labels to be one of the most important factors in their food purchasing decisions. In fact, one additional level of interest in produce freshness leads to almost nine percent rise in the likelihood of buying local. On the other hand, an extra level of interest in organically grown products decreases the likelihood of "locally grown" products being the most preferred, and vice versa. This finding posits that "organic" and "local" are substitutes. In other words, increased preferences for one (say organic) suggest more quantity of it will be demanded and less quantity demanded for the other (local). When combined together, only those shoppers with higher interests in organic produce indicate a significant consideration for both local and organic food labels. This means that although respondents were informed "organic, regardless of where it is grown", they desire those organic food products to be locally grown.

The relative likelihood for an online shopper to primarily consider labels with "organically grown" food products is estimated to be seven percent only. Unlike for "local" labels, we found that income positively impact preferences for "organic" produce. Those shoppers whose income is above participants' average income $(\$ 62,539)$ indicated that "organic" labels are most important. This result is similar to Nasir et al. (2014) who found that in addition to females, relatively affluent consumers are more likely to purchase organic foods. While insignificant for local labels, we found that married couples are almost five percent less likely to consider organically grown labored food products as the most important their food purchasing decisions. Similarly, locavore consumers are nine percent less likely to consider organically grown labored food products as the most important their food purchasing decisions. We also found that those respondents with high interests in locally grown fresh produce do not consider "organically grown" labeled food products as the most important. On a 1-5 scale, one additional level of interest in local fresh produce decreases the likelihood of considering organic labels by three percent. Similarly, those shoppers with high interests in the freshness of the food products do not consider "organically grown" labels as one of the most important factors in their food purchasing decisions. Results indicate that one additional level of interest in produce freshness reduces the likelihood of buying organic by almost three percent. On the other hand, an extra level of interest in organically grown products increases the likelihood of "organically grown" products being the most preferred by eight percent barely.

We estimated that the relative probability that an online shopper primarily considers both "locally and organically grown" food products is 24 percent. This likelihood is significantly higher among those shoppers who have high 
interests in learning about direct-to-consumer market outlets and those with high interests in organically grown fresh produce. We found that those with low interests in product freshness indicate that they primarily seek for labels that show both organic and local food products. One additional level of interest in local fresh produce decreases the likelihood of considering both local and organic labels by 4 percent.

Respondents who have other food labels (beside prices, local and/or organic) they consider as the most important in making their purchasing decisions had an opportunity to indicate so. Results indicate that the relative likelihood for a random online shopper to primarily consider other food labels is 23 percent. Caucasians are 13 percent less likely to prefer food labels. Likewise, locavore consumers are almost seven percent less probable to prefer other food labels. In fact, we reported that they are 20 percent more likely to prefer "locally grown" food products. We further found that those shoppers with high interests in learning about direct-to-consumer market outlets in their community are less probable to prefer other labels. An extra level in these interests decreases that likelihood by almost 14 percent. Similarly, one additional level of interests in local fresh produce lowers the probability of considering any other food labels as the most important when making purchasing decisions by almost four percent. One additional level of interests in organic fresh produce diminishes that probability by almost seven percent. These results suggest that the more interested consumers are in local and/or organic produce, the lesser their interests in other food labels. This posits that food labels allow product substitutability more apparent.

\section{Conclusion}

Online shopping is increasingly becoming a common shopping venue for several consumers. However, preferences for fresh produce among those who frequently shop online are still unclear. This study has focused primarily on preferences for food labels (other than prices) among online shoppers. We used descriptive statistics to describe characteristics of online shoppers, a binary logit model to explain the likelihood of considering food labels when purchasing food products, and a multinomial logit model to estimate relative probabilities for a specific food label to be the most important. We found that the likelihood for online shoppers to consider food labels into their purchasing decision-making is 86 percent. We further found that the relative probability for locally grown labels to be the most important is 46 percent, seven percent for "organically grown", 24 percent for both local and organic, and 23 percent for other kinds of labels.

This study is significantly pertinent to those in the agriculture community. These results are important for food growers, processors, and agricultural marketers/sellers. Since the probability to consider food labels into purchasing decisions is very high ( 86 percent), food labeling should continue being part of marketing strategies. Results suggest that local food growers/marketers should look at the online market as an opportunity to explore. This is because "locally grown" is the most preferred among the online shoppers. We suggest that the organic growers will most likely succeed by selling their products locally. Because the likelihood of primarily preferring other labels is 23 percent, we suggest that labeling programs/strategies be inclusive as much as possible. In other words, food labels indicating information like prices, place of origin, production methods, nutrition facts, expiration dates are very useful and consequently, need to stay enforced. Finally, we encourage future research studies to further research about this topic. Specifically, we suggest that they focus on explaining consumer preferences for online shopping for fresh produce. It would also be useful to extend the study to other regions of the country (beyond South region) and check whether preferences for food labels among online differ across regions.

\section{References}

Acosta, L. (2014). Restrictions on Genetically Modified Organisms: United States. Retrieved from https://www. loc.gov/law/help/restrictions-on-gmos/usa.php\#Foodstuffs

Baryeh, K. (2015). Preferences and willingness to pay more for organic foods by Tennessee consumers (Unpublished doctoral dissertation, Tennessee State University).

Berning, J., \& Campbell, B. (2016). Consumer Knowledge, Perception and Acceptance of GMOs (No. 1377-2016-109855). Paper presented at the Southern Agricultural Economics Association 2016 Annual Meeting, Mobile, AL. Retrieved from https://ageconsearch.umn.edu/bitstream/252769/2/paper-GMO\%20 Labels.pdf

Bruno, C. C., \& Campbell, B. L. (2016). Students' willingness to pay for more local, organic, non-GMO and general food options. Journal of Food Distribution Research, 47(3), 32-48.

Byrd, E. S., Widmar, N. J. O., \& Wilcox, M. D. (2017). Are Consumers Willing to Pay for Local Chicken Breasts and Pork Chops? Journal of Food Products Marketing, 24(2), 235-248. https://doi.org/10.1080/ 10454446.2016.1266556 
Center for Food Safety. (2017). Campaigns. Washington, DC: Center for Food Safety.

Chen, X. (2015). Consumers' willingness to pay for organic and local food: An experimental study using structural equation modeling (Unpublished Master's Thesis, University of Delaware, USA).

Cholette, S., Özlük, Ö., Özşen, L., \& Ungson, G. R. (2013). Exploring purchasing preferences: Local and ecologically labelled foods. Journal of Consumer Marketing, 30(7), 563-572. https://doi.org/10.1108/ JCM-04-2013-0544

Curtis, K. R., Gumirakiza, J. D., \& Bosworth, R. (2014). Consumer Preferences and Willingness to Pay for Multi-Labeled Produce at Farmers' Markets. Journal of Food Distribution Research, 45(1), 14-20.

DeJonge, J., \& Trijp, V. H. (2013). Meeting Heterogeneity in Consumer Demand for Animal Welfare: A Reflection on Existing Knowledge and Implications for the Meat Sector. Journal of Agricultural and Environmental Ethics, 26(3), 629-661. https://doi.org/10.1007/s10806-012-9426-7

DeJonge, J., \& Trijp, V. H. (2013). The impact of broiler production system practices on consumer perceptions of animal welfare. Poultry Science, 92(12), 3080-3095. https://doi.org/10.3382/ps.2013-03334

De-Magistris, T., \& Gracia, A. (2016). Consumers' willingness to pay for light, organic and PDO cheese: An experimental auction approach. British Food Journal, 118(3), 560-571. https://doi.org/10.1108/BFJ-092015-0322

Dobnik, D., Spilsberg, B., Košir, A. B., Holst-Jensen, A., \& Zel, J. (2015). Multiplex quantification of 12 European Union authorized genetically modified maize lines with droplet digital polymerase chain reaction. Analytical Chemistry, 87(16), 8218-8226. https://doi.org/10.1021/acs.analchem.5b01208

Ducrot, P., Julia, C., Méjean, C., Kesse-Guyot, E., Touvier, M., Fezeu, L. K., Hercberg, S., \& Péneau, S. (2016). Impact of Different Front-of-Pack Nutrition Labels on Consumer Purchasing Intentions: A Randomized Controlled Trial: A Randomized Controlled Trial. American Journal of Preventive Medicine, 50(5), 627-636. https://doi.org/10.1016/j.amepre.2015.10.020

Feldmann, C., \& Hamm, U. (2015). Consumers' perceptions and preferences for local food: A review. Food Quality and Preference, 40(A), 152-164. https://doi.org/10.1016/j.foodqual.2014.09.014

Findling, M. T. G., Werth, P. M., Musicus, A. A., Bragg, M. A., Graham, D. J., Elbel, B., \& Roberto, C. A. (2017) Comparing five front-of-pack nutrition labels' influence on consumers' perceptions and purchase intentions. Preventive Medicine, 106, 114-121. https://doi.org/10.1016/j.ypmed.2017.10.022

Gustat, J., O’Malley, K., Luckett, B. G., \& Johnson, C. C. (2015). Fresh produce consumption and the association between frequency of food shopping, car access, and distance to supermarkets. Preventive Medicine Reports, 2, 47-52. https://doi.org/10.1016/j.pmedr.2014.12.009

Hallman, W. K., Cuite, C. L., \& Morin, X. K. (2013). Public perceptions of labeling genetically modified foods. Rutgers School of Environ. Sci., 2013-2001.

Hemphill, T. A., \& Banerjee, S. (2015). Genetically Modified Organisms and the US Retail Food Labeling Controversy: Consumer Perceptions, Regulation, and Public Policy. Business and Society Review, 120(3), 435-464. https://doi.org/10.1111/basr.12062

Heng, Y., Peterson, H. H., \& Li, X. (2016). Consumer Responses to Multiple and Superfluous Labels in the Case of Eggs. Journal of Food Distribution Research, 47(2), 62-82.

Hsu, C., \& Chen, C. (2011). Analyzing the purchase motivation of online shopping for health food. African Journal of Business Management, 5(12), 4699-4703.

Hwang, J., Lee, K., \& Lin, T. N. (2016). Ingredient labeling and health claims influencing consumer perceptions, purchase intentions, and willingness to pay. Journal of Foodservice Business Research, 19(4), 352-367. https://doi.org/10.1080/15378020.2016.1181507

Karim, R. A. (2013). Customer satisfaction in online shopping: A study into the reasons for motivations and inhibitions. Journal of Business and Management, 11(6), 13-20. https://doi.org/10.9790/487X-1161320

Kennedy, P. (2008). A Guide to Econometrics (6th ed.). Malden, MA: Blackwell Publishing.

Lang, M., Stanton, J., \& Qu, Y. (2014). Consumers' evolving definition and expectations for local foods. British Food Journal, 116(11), 1808-1820. https://doi.org/10.1108/BFJ-03-2014-0117 
Larceneux, F., Benoit-Moreau, F., \& Renaudin, V. (2012). Why Might Organic Labels Fail to Influence Consumer Choices? Marginal Labelling and Brand Equity Effects. Journal of Consumer Policy, 35(1), 85-104. https://doi.org/10.1007/s10603-011-9186-1

Lee, W., Shimizu, M., Kniffin, K., \& Wansink, B. (2013). You taste what you see: Do organic labels bias taste perceptions? Food Quality and Preference, 29(1), 33-39. https://doi.org/10.1016/j.foodqual.2013.01.010

Lian, J. W., \& Yen, D. C. (2014). Online shopping drivers and barriers for older adults: Age and gender differences. Computers in Human Behavior, 37, 133-143. https://doi.org/10.1016/j.chb.2014.04.028

Mas-Colell, A., Whinston, M. D., \& Green, J. R. (1995). Microeconomic Theory. New York, NY: Oxford University Press.

Nasir, V. A., \& Karakaya, F. (2014). Consumer segments in organic foods market. Journal of Consumer Marketing, 31(4), 263-277. https://doi.org/10.1108/JCM-01-2014-0845

Neilson Holdings PLC. (2015). The future of grocery. E-comerce, digital technology, and changing shopping preferences around the world. New York, NY: Neilson Holdings PLC.

Newman, C. L., Burton, S., Andrews, J. C., Netemeyer, R. G., \& Kees, J. (2017). Marketers' use of alternative front-of-package nutrition symbols: An examination of effects on product evaluations. Journal of the Academy of Marketing Science, 1-24. https://doi.org/10.1007/s11747-017-0568-z

Oraman, Y. (2014). An Analytic Study of Organic Food Industry as Part of Healthy Eating Habit in Turkey: Market Growth, Challenges and Prospects. Procedia-Social and Behavioral Sciences, 150, 1030-1039. https://doi.org/10.1016/j.sbspro.2014.09.115

Pouta, E., Heikkilä, J., Forsman-Hugg, S., Isoniemi, M., \& Mäkelä, J. (2010). Consumer choice of broiler meat: The effects of country of origin and production methods. Food Quality and Preference, 21(5), 539-546. https://doi.org/10.1016/j.foodqual.2010.02.004

Racine, E. F., Mumford, E. A., Laditka, S. B., \& Lowe, A. E. (2012). Understanding Characteristics of Families Who Buy Local Produce. Journal of Nutrition Education and Behavior, 45(1), 30-38. https://doi.org/ 10.1016/j.jneb.2012.04.011

Sackett, H., Shupp, R., \& Tonsor, G. (2016). Differentiating "sustainable" from "organic" and "local" food choices: does information about certification criteria help consumers? International Journal of Food and Agricultural Economics, 4(3), 17-31.

Schmidheiny, K. (2007). Multinomial choice (basic models). Retrieved from https://www.schmidheiny.name/ teaching/multinomialchoice2up.pdf

Stanton, J. L., Wiley, J. B., \& Ferdinand, F. W. (2012). Who are the locavores? Journal of Consumer Marketing, 29(4), 248-261. https://doi.org/10.1108/07363761211237326

Train, K. E. (2009). Discrite Choice Methods with Simulation (2nd ed.). New York, NY: Cambridge University Press. https://doi.org/10.1017/CBO9780511805271

U.S. Census Bureau. (2016). Census Regions and Divisions of the United States. Retrieved from http://www2.census.gov/geo/pdfs/maps-data/maps/reference/us_regdiv.pdf

Vanhonacker, F., \& Verbeke, W. (2014). Public and consumer policies for higher welfare food products: Challenges and opportunities. Journal of Agricultural and Environmental Ethics, 27(1), 153-171. https://doi.org/10.1007/s10806-013-9479-2

VanLoo, E. J., Caputo, V., Nayga, R. M., \& Verbeke, W. (2014). Consumers' valuation of sustainability labels on meat. Food Policy, 49(1), 137-150. https://doi.org/10.1016/j.foodpol.2014.07.002

VanLoo, E. J., Caputo, V., Nayga, R. M., Meullenet, J. F., \& Ricke. S. C. (2011). Consumers' willingness to pay for organic chicken breast: Evidence from choice experiment. Food Quality and Preference, 22(7), 603-613. https://doi.org/10.1016/j.foodqual.2011.02.003

Wooldridge, J. M. (2009). Introductory Econometrics; A Modern Approach (4th ed.). Mason, IA: South-Western Cengage Learning.

Wunderlich, S., \& Gatto, K. A. (2015). Consumer perception of genetically modified organisms and sources of information. Advances in Nutrition: An International Review Journal, 6(6), 842-851. https://doi.org/ 10.3945/an.115.008870

Zepeda, L., \& Li, J. (2006). Who Buys Local Food? Journal of Food Distribution Research, 37(3), 5-15. 
Zhang, L., Gao, Z., \& Vassalos, M. (2016). Sustainable Consumer Groups and Their Willingness to Pay for Tangible and Intangible Attributes of Fresh Strawberries. Paper presented at the Southern Agricultural Economics Association Annual meeting, San Antonio, TX. Retrieved from http://ageconsearch.umn.edu/ record $/ 230060 ? \ln =$ en

\section{Copyrights}

Copyright for this article is retained by the author(s), with first publication rights granted to the journal.

This is an open-access article distributed under the terms and conditions of the Creative Commons Attribution license (http://creativecommons.org/licenses/by/4.0/). 